\title{
Predicting Indian Ocean Cyclone Parameters Using an Artificial Intelligence Technique
}

\author{
C. Purna Chand \\ APSDMA \\ M.M.Ali ( $D$ mmali110@gmail.com) \\ FSU: Florida State University \\ B. Himasri \\ APSDMA \\ Mark A Bourassa \\ FSU: Florida State University \\ Yangxing Zheng \\ FSU: Florida State University
}

\section{Research Article}

Keywords: cyclone track, wind speed, pressure, landfall point, Climate Stewardship (IBTrACS), National Oceanic and Atmospheric Administration (NOAA).

Posted Date: July 7th, 2021

DOI: https://doi.org/10.21203/rs.3.rs-659763/v1

License: @ (i) This work is licensed under a Creative Commons Attribution 4.0 International License. Read Full License 


\section{Abstract}

Precise prediction of a cyclone track with wind speed, pressure, landfall point and the time of crossing the land are very essential for the disaster management and mitigation including the evacuation processes. In this paper, we use an artificial neural network (ANN) approach to estimate the cyclone parameters. For this purpose, these parameters are obtained from the International Best Track Archive for Climate Stewardship (IBTrACS), National Oceanic and Atmospheric Administration (NOAA). Since ANN benefits from a large number of data points, each cyclone is divided into different segments. We use the past information to predict the cyclone geophysical parameters. The predicted values are compared with the observations.

\section{Introduction:}

A tropical cyclone (TC) is one of the deadliest and most damaging natural disasters affecting people, livestock, agriculture and the economics of the coastal areas. Reductions in uncertainty are of great benefit for the disaster management authorities to plan for the evacuation and mitigation processes (Willoughby et al., 2007; Lazo et al., (2010). The major components of cyclone warnings are the forecasts of the track, winds and pressure in addition to the precise landfall point with the time of crossing the land. Predicting the track of a cyclone helps in knowing the direction in which it is moving and the area it is likely to affect. The intensity is primarily estimated from the maximum sustained wind speed, which provides a measure for the severity of a cyclone. The wind is one of the major hazards associated with a TC creating damage to houses, bridges, electrical poles, mangroves and the ecosystem. Although the damage in the coastal region is high, inland damage cannot be ruled out. Strong winds are present at the eyewall of a cyclone. The intensity of the cyclone together with the wind speed and the pressure helps in predicting the storm surge, although the spatial extent of the storm and the direction of travel are also important in predicting storm surge. Strom surge is the most devastating component of the cyclones, particularly for coasts, such as are typical for India, that have a highly varying bathymetry. Since bathymetry is one of the most critical components in estimating the storm surge, even a slight error in predicting the landfall point can lead to a different storm surge heights. The time of crossing is used to include the impacts of tides and helps in arranging the evacuation process. Thus, location, winds and the pressure of a cyclone, landfall point with the time of crossing the land are the critical components in predicting the storm surge.

Several dynamical, statistical and statistical-dynamic models have been developed to predict the cyclone parameters. Mohanty and Gupta (1997) and Gupta (2006) summarised different track prediction techniques. Bell (1979) described the operational forecasting models. Ali et al., (2007) summarised different approaches used in predicting the cyclones. They used Artificial Neural Network (ANN) technique to predict the position of the cyclone alone in terms of the latitude and longitude using the past 12 hours observations. In this paper, we attempt to use the same technique to predict winds, pressure and landfall as well, in addition to the storm location in terms of latitude and longitude.

ANN is one of the powerful data mining tools for computing input-output relationships. It is an information processing paradigm that works somewhat like hypothesized biological system in the human brain. ANN consists of an interconnected assembly of models, whose functionality is based on a neuron (Swain et al., 2006). The analysis can be used as a standalone application or as a complement to statistical analysis. This non-dynamic numerical model has been used in many oceanographic (Aliet al., 2004, Tolman et al., 2005, Jain and Ali 2006, Swain et al., 2006, Jain et al., 2007, Ali et al., 2012a, b, c) and in meteorological studies (Liu et al., 1997, Ali et al., 2007, Sharma and Ali., 2012). This technique is also found useful for satellite parameter retrievals (Krasnopolsky and Schiller., 2003, Ali et al., 2015, Sharma et al., 2013, Ali et al., 2016). ANN requires three sets of data, one for training, one for verification and the other for validation. The first dataset is used to train the model, the second dataset to test the model for any shortcomings and finally, the validation dataset is used in statistical parameter estimation. The validation dataset is an independent data that is not considered in developing the model. The popular ANN models are radial basis functions (RBF) and multilayer perceptions (MLP). In an ANN model, both the input and the output variables are normalized to vary between 0 and 1 .

\section{Date And Methodology:}

\subsection{Data}

Cyclone parameters available over the north Indian Ocean from IBTrACS (International Best Track Archive for Climate Stewardship,

https://www.ncei.noaa.gov/data/international-best-track-archive-for-climate-stewardship-ibtracs/v04r00/access/csv/) during 1971-2019 have been used in this analysis. IBTrACS provide information on cyclones from different sources. Here, we used JTWC (Joint Typhoon Warning Center) data alone. These data contain latitude, longitude, surface pressure and wind speed of cyclones. Although these data are available both at 3 and 6 hourly intervals, we used only 6-hour interval data in this study. The wind filed data are available from 1973 to 2019, the pressure filed data from 2001 to 2019 , while the position (latitude and longitude) is available from 1971 to 2019. Those cyclone positions which are at irregular intervals were discarded and after this elimination 323 cyclones were studied for the position, 239 cyclones for wind speed and 104 cyclones for pressure An ANN approach is used to forecast future position using past cyclone observations. The tracks are segmented to provide the number of records required by ANN. The selection of training, verification and validation is described in the next section.

\subsection{Segmentation of the tracks}

ANN requires a large number of points to develop the model, therefore each cyclone track has been divided into different segments. For example, the present position and past two sequential six-hourly positions in terms of latitude and longitude are considered as predictors and the next six hourly positions as the predictand for 06 hours past positions and 06 hours forecast position using the six hourly interval data. Thus, if the present position is at 12 hours, locations of 06,09 and 12 hours are the predictors (past positions) and the location at 18 hours is the predictand (forecast position). Similarly, if the present position is 18 hours, locations of 09,12 and 18 hours are the predictors and the position at 24 hours is the predictand. Besides 06 hours 
forecast, 12,18 and 24 hours forecasts are also considered with the past 06 hours positions. Similarly, past 12 hours positions are used to forecast 06,12 , 18 and 24 hours in advance. This type of segmentation increases the number of points for ANN analysis. Similar segmented data sets were created using the 6-hourly interval data as well. Thus, altogether 8 sets of data have been studied with past 6 hours and 12 hours, each of these two past hours having the predictions for $06,12,18$ and 24 hours.

Since ANN needs three sets of data one for training, one for verification and the other for validation, out of the total number of 49 years of the data on latitude and longitude from 1971 to 2019, 20 years from 1971 to 1990 are used for training, 17 years from 1991 to 2007 for verification and 12 years from 2008 to 2019 for validation. The same analysis was repeated for cyclone wind speed and pressure. The period of study, the number of past hours used as predictors and the hour of forecast as predictand, total number of segments used for training, verification and validation for cyclone position, wind speed and pressure are given in table-1. The first column in the table indicates the past number of hours used as the predictors and the second column indicates the hours in advance for which the forecast is given as the predictant. The total number of points in each dataset depends on the type of segmentation and the period of the data availability as explained earlier. Thus, the number of points will decrease as the forecasted time increase from 6-hours to 24 -hours, besides the past number of hours used as predictors. The past number of hours 06 hours and forecasted time 06 hours has the past 6 -hours position including the current position as the predictor and the future 6-hour position as the predictand.

Table-1: Number of Sectors used to compute the cyclone position, pressure and wind speed. 


\begin{tabular}{|c|c|c|c|c|c|}
\hline \multicolumn{6}{|c|}{ Latitude / Longitude (degrees) } \\
\hline $\begin{array}{l}\text { Past hours used for } \\
\text { prediction }\end{array}$ & $\begin{array}{l}\text { Forecasted } \\
\text { Hour }\end{array}$ & $\begin{array}{l}\text { Total No. of } \\
\text { Sectors }\end{array}$ & $\begin{array}{l}\text { No. of Train } \\
\text { Sectors }\end{array}$ & $\begin{array}{l}\text { No. of Verification } \\
\text { Sectors }\end{array}$ & $\begin{array}{l}\text { No. of Validation } \\
\text { Sectors }\end{array}$ \\
\hline 06 & 06 & 6245 & 2165 & 2747 & 1333 \\
\hline 06 & 12 & 5923 & 2072 & 2587 & 1264 \\
\hline 06 & 18 & 5602 & 1979 & 2428 & 1195 \\
\hline 06 & 24 & 5283 & 1886 & 2271 & 1126 \\
\hline 12 & 06 & 5923 & 2072 & 2587 & 1264 \\
\hline 12 & 12 & 5602 & 1979 & 2428 & 1195 \\
\hline 12 & 18 & 5283 & 1886 & 2271 & 1126 \\
\hline 12 & 24 & 4967 & 1793 & 2117 & 1057 \\
\hline Years considered: & & & $1991-2007$ & $1971-1900$ & 2008-2019 \\
\hline \multicolumn{6}{|l|}{ Wind Speed (Knots) } \\
\hline $\begin{array}{l}\text { Past hours used for } \\
\text { prediction }\end{array}$ & $\begin{array}{l}\text { Forecasted } \\
\text { Hour }\end{array}$ & $\begin{array}{l}\text { Total No. of } \\
\text { Sectors }\end{array}$ & $\begin{array}{l}\text { No. of Train } \\
\text { Sectors }\end{array}$ & $\begin{array}{l}\text { No. of Verification } \\
\text { Sectors }\end{array}$ & $\begin{array}{l}\text { No. of Validation } \\
\text { Sectors }\end{array}$ \\
\hline 06 & 06 & 4757 & 2165 & 1268 & 1324 \\
\hline 06 & 12 & 4519 & 2072 & 1191 & 1256 \\
\hline 06 & 18 & 4282 & 1979 & 1115 & 1188 \\
\hline 06 & 24 & 4045 & 1886 & 1039 & 1120 \\
\hline 12 & 06 & 4519 & 2072 & 1191 & 1256 \\
\hline 12 & 12 & 4282 & 1979 & 1115 & 1188 \\
\hline 12 & 18 & 4045 & 1886 & 1039 & 1120 \\
\hline 12 & 24 & 3809 & 1793 & 964 & 1054 \\
\hline Years considered: & & & $1991-2007$ & 1973-1990 & 2008-2019 \\
\hline \multicolumn{6}{|l|}{ Pressure (hPa) } \\
\hline $\begin{array}{l}\text { Past hours used for } \\
\text { prediction }\end{array}$ & $\begin{array}{l}\text { Forecasted } \\
\text { Hour }\end{array}$ & $\begin{array}{l}\text { Total No. of } \\
\text { Sectors }\end{array}$ & $\begin{array}{l}\text { No. of Train } \\
\text { Sectors }\end{array}$ & $\begin{array}{l}\text { No. of Verification } \\
\text { Sectors }\end{array}$ & $\begin{array}{l}\text { No. of Validation } \\
\text { Sectors }\end{array}$ \\
\hline 06 & 06 & 2066 & 632 & 742 & 692 \\
\hline 06 & 12 & 1962 & 599 & 706 & 657 \\
\hline 06 & 18 & 1858 & 566 & 670 & 622 \\
\hline 06 & 24 & 1754 & 533 & 634 & 587 \\
\hline 12 & 06 & 1962 & 599 & 706 & 657 \\
\hline 12 & 12 & 1858 & 566 & 670 & 622 \\
\hline 12 & 18 & 1754 & 533 & 634 & 587 \\
\hline 12 & 24 & 1650 & 500 & 598 & 552 \\
\hline Years considered: & & & $2008-2013$ & $2001-2007$ & 2014-2019 \\
\hline
\end{tabular}

\subsection{Distance between landfall points of the observed and predicted tracks:}

ArcGIS software has been used in computing the distance between the landfall point of the predicted and observed tracks. First, a "feature layer" of the observed and predicted cyclone positions based on the $\mathrm{X}$ - and $\mathrm{y}$-coordinates as defined in the data file is created using "display XY data". Then, the cyclone tracks have been created by joining the points as a line based on a unique values obtained from the year and cyclone number using "points to line" tool. Using the "intersect tool", the intersection points of the coast with the two cyclone tracks have been computed. In case a cyclone passes from one bay to the other, for example, from the Arabian Sea to the Bay of Bengal, only that point when the cyclone entered the land for the first time is considered. Secondly, if the coastal line has a curvature and if the cyclone passed thourgh this curved area, then the first crossing point onto the land is considered as the intersection point. A CSV file is then created consisting of the $x$ - and $y$-coordinate points and the unique codes with combination of year and cyclonic number. Based on the values in a start $x$-coordinate field, start $y$-coordinate field of the observed track and the end $x$-coordinate field, and end $y$-coordinate 
field of the predicted track, a new feature class containing geodetic line feature is created using XY to line tool. Finally, the distance between the two landfall points is computed from the length of the line joining the intersection points using the "Add geometry attribute tool".

\section{Results And Discussion:}

The cyclone position in terms of latitude and longitude, pressure and wind speed are estimated from an ANN approach and compared with the observations in the following sections.

\subsection{Comparison of the position:}

Forecast of the cyclone position in terms of the latitude and longitude are predicted for 6, 12, 18 and 24 hours in advance each using 6 and 12 hours past positions. Thus, there are two forecasts for $06,12,18$ and 24 hours using 6 and 12 hours past positions. Thus, we have altogether eight forecasts. The forecasts are given for the latitude and longitude separately in table - 2. The statistics for longitude are given in parenthesis. The Pearson Correlation Coefficient (CC) for all forecasts for all the data sets is more than 0.97 , which shows that the estimations are accurate for the three data sets of training, testing and validation. Almost similar values for all the statistical parameters for the three data sets indicate that the three data sets are of similar characteristics. For all the forecasts of training, testing and validation sets, the Absolute Residual Mean (ARM) and Root Mean Square Error (RMSE) for longitude are more than those for latitude. This is because the longitude values (ranging from 50 to 100 degrees) are greater than the latitude values (ranging from 0 to 25 degrees). Hence, we computed the Scatter Index (SI), which is the RMSE normalised to the observed mean value. The SI, thus computed, of the error in longitude is significantly less by $>50 \%$ than the error in latitude. This result concludes that the prediction of east-west moving cyclones is more accurate than the prediction of North-South moving cyclones. This interpretation is supported by consistently better correlation coefficients for longitude. However, the RMSE for longitude is larger than for longitude. It is the wider range of value for longitude that leads to the different interpretations of these measures of skill. Emergency managers will probably find the RMSE value more useful, however, by other metrics the skill in longitude forecasts is greater than the skill in latitude forecasts.

The comparison of SI for the validation data set for various past and lead hours are shown in figure-III(a). As discussed previously the error in longitude is less than that in latitude in all the four cases with 6 hourly past data. Secondly, the increase of error with lead time is also less for longitude compared to latitude. However, the errors are insignificant for both latitude and longitude.

The Mean Distance Error (MDE) between the observed and predicted positions was computed using 6 and 12 hour past positions for the lead hours of 6 , 12 , 18 , and 24 hours. Thus, altogether 8 forecasts are given as shown in Figure-I. This error, for all the cyclones together, varies from $30.7 \mathrm{~km}$ (06P06F) to 151.7 $\mathrm{km}$ (12P24F). For example, the mean distance error for the 6-hour past positions (as input) and 24-hour lead position (as the output) is 139.14 km (06 $24 \mathrm{~F}$ in Figure-I). Ali et al., (2007) reported a MDE of $137.5 \mathrm{~km}$ by ANN and $182.5 \mathrm{~km}$ by CLIPER approach for the same 6-hour past positions (as input) and 24hour lead position (as the output). The MDE between the best track and predicted tracks are almost the same for six hour ANN forecasts based on 6 hour lead time and 12 hour lead time.

The error increases from 6 hours forecast $(30.68 \mathrm{Km})$ to 24 hours forecast $(139.14 \mathrm{~km})$ for 6 hourly interval data by considering the 6 hours past positions. Similarly, the error increases from 6 hours forecast $(32.99 \mathrm{~km})$ to 24 hours forecast $(151.68 \mathrm{~km})$ by considering the 12 hours past positions. Among the 323 cyclones from the validation dataset, four have been randomly selected that did not have a straight path. A comparison of the best track and the predicted track for these cyclones is shown in Figure-ll. The very severe cyclonic storm, Phet, from 31 May to 6 June 2010 (Figure-lla) first moved north westward, curved after passing over the land and moved northeast ward. The ANN predicted track almost followed this best track with a MDE of $82.5 \mathrm{~km}$ for cyclone Phet. Another very severe cyclonic storm Madi during 5-12 December 2013 (Figure-llb) has re-tracked after moving northeast ward and predicted track is similar to the best track with a MDE of $53.1 \mathrm{~km}$ which is the least among these four cyclones. Gaja, another severe cyclonic storm during 11-18 November 2018 re-looped almost in the beginning itself in the Bay of Bengal, crossed the Indian landmass and moved over the Arabian Sea with MDE of $75 \mathrm{~km}$. The extremely severe cyclonic storm, Maha from 30 October to 6 November 2019 has the largest MDE of $87.8 \mathrm{~km}$. the errors are large in the beginning but reduced afterwards.

\subsection{Estimation of wind speed:}

Statistical parameters such as ARM, RMSE, SI and CC for all the 8 data sets for training, verification and validation are given in table-2. The CC is more than 0.78 for all the estimations of the validation dataset. The RMSE varies between 5 and 16 knots depending upon the lead time. The SI, which is one of the best statistical parameters to interpret any estimation, varies between $\sim 0.1$ for 6 hours advance prediction to $\sim 0.3$ for 24 hours advance prediction for validation dataset (Table-2 and Figure-IIlb). The values increase with the lead time and this increase is the same irrespective of the past number of 6 or 12 hours.

\subsection{Estimation of Pressure:}

Estimation of pressure fields of Tropical Cyclones is one of the major problems. The statistical parameters in the estimation of pressure for all the 8 data sets are given in table-2. The RMSE for the validation dataset varies from $4.9 \mathrm{hPa}$ to $13.7 \mathrm{hPa}$, the error increasing with the lead time. The errors are large as the absolute values themselves are large (of the order of $1000 \mathrm{hPa}$ ). Purnachand et al., (2014) using the University of Washington Planatary Boundary Layer (UWPBL) model of Patoux et al., (2003) estimated the pressure in cyclone, Nilam using the Ocean Sat-II Scatterometer wind fields. This model has an option providing the background pressure values. The RMSE from this model is $4.97 \mathrm{hPa}$ if a standard pressure of $1013 \mathrm{hPa}$ was given. But the error reduced to $0.67 \mathrm{hPa}$ if pressure values of all the available buoys were utilized. However, in the present paper we did not use any pressure observations as input. We simply used the past values and predicted the future values. Hence, our errors are comparable with providing the standard pressure of $1013 \mathrm{hPa}$.

Page 5/11 
However, the S.I is very small for all the 8 datasets varying between 0.0050 and 0.0138 for the validation dataset. The S.I's by using 6 hours past position and 12 hours past positions are shown in figure IIlc. The values increased with the forecast lead time and this increase is the same irrespective of the past number of 6 or 12 hours.

Table-2: The statistical parameters such as Absolute Residual Mean (ARM), Root Mean Square Error (RMSE), Scatter Index (SI) and Correlation Coefficient (CC) for Latitude (Longitude), Wind Speed and Pressure.

\begin{tabular}{|c|c|c|c|c|c|c|c|c|c|c|c|c|}
\hline \multicolumn{13}{|c|}{ Latitude (Longitude) } \\
\hline \multirow{2}{*}{$\begin{array}{l}\text { Forecast } \\
\text { Time }\end{array}$} & \multicolumn{4}{|l|}{ Train } & \multicolumn{4}{|c|}{ Verification } & \multicolumn{4}{|c|}{ Validation } \\
\hline & ARM & RMSE & SI & $\mathrm{CC}$ & ARM & RMSE & SI & $\mathrm{CC}$ & ARM & RMSE & SI & $\mathrm{CC}$ \\
\hline 06P 06F & $\begin{array}{l}0.1266 \\
(0.1629)\end{array}$ & $\begin{array}{l}0.1777 \\
(0.2539)\end{array}$ & $\begin{array}{l}0.0106 \\
(0.0032)\end{array}$ & $\begin{array}{l}0.9994 \\
(0.9997)\end{array}$ & $\begin{array}{l}0.1384 \\
(0.1533)\end{array}$ & $\begin{array}{l}0.1991 \\
(0.2175)\end{array}$ & $\begin{array}{l}0.0142 \\
(0.0027)\end{array}$ & $\begin{array}{l}0.9993 \\
(0.9998)\end{array}$ & $\begin{array}{l}0.1671 \\
(0.1902)\end{array}$ & $\begin{array}{l}0.2393 \\
(0.275)\end{array}$ & $\begin{array}{l}0.0167 \\
(0.0036)\end{array}$ & $\begin{array}{l}0.9983 \\
(0.9998)\end{array}$ \\
\hline $06 \mathrm{P} 12 \mathrm{~F}$ & $\begin{array}{l}0.2918 \\
(0.4009)\end{array}$ & $\begin{array}{l}0.3999 \\
(0.5954)\end{array}$ & $\begin{array}{l}0.0238 \\
(0.0075)\end{array}$ & $\begin{array}{l}0.9971 \\
(0.9983)\end{array}$ & $\begin{array}{l}0.3228 \\
(0.3699)\end{array}$ & $\begin{array}{l}0.4450 \\
(0.5056)\end{array}$ & $\begin{array}{l}0.0315 \\
(0.0064)\end{array}$ & $\begin{array}{l}0.9967 \\
(0.9991)\end{array}$ & $\begin{array}{l}0.3395 \\
(0.4144)\end{array}$ & $\begin{array}{l}0.4676 \\
(0.579)\end{array}$ & $\begin{array}{l}0.0325 \\
(0.0076)\end{array}$ & $\begin{array}{l}0.9938 \\
(0.9991)\end{array}$ \\
\hline 06P 18F & $\begin{array}{l}0.4771 \\
(0.666)\end{array}$ & $\begin{array}{l}0.6397 \\
(0.9475)\end{array}$ & $\begin{array}{l}0.0378 \\
(0.0120)\end{array}$ & $\begin{array}{l}0.9926 \\
(0.9959)\end{array}$ & $\begin{array}{l}0.528 \\
(0.6086)\end{array}$ & $\begin{array}{l}0.7085 \\
(0.823)\end{array}$ & $\begin{array}{l}0.0498 \\
(0.0105)\end{array}$ & $\begin{array}{l}0.9913 \\
(0.9975)\end{array}$ & $\begin{array}{l}0.5275 \\
(0.672)\end{array}$ & $\begin{array}{l}0.7027 \\
(0.9164)\end{array}$ & $\begin{array}{l}0.0485 \\
(0.0121)\end{array}$ & $\begin{array}{l}0.9859 \\
(0.9979)\end{array}$ \\
\hline 06P 24F & $\begin{array}{l}0.6583 \\
(0.9402)\end{array}$ & $\begin{array}{l}0.8664 \\
(1.2806)\end{array}$ & $\begin{array}{l}0.0509 \\
(0.0162)\end{array}$ & $\begin{array}{l}0.9864 \\
(0.9925)\end{array}$ & $\begin{array}{l}0.7226 \\
(0.8784)\end{array}$ & $\begin{array}{l}0.9641 \\
(1.1591)\end{array}$ & $\begin{array}{l}0.0673 \\
(0.0148)\end{array}$ & $\begin{array}{l}0.9838 \\
(0.9953)\end{array}$ & $\begin{array}{l}0.7261 \\
(0.8954)\end{array}$ & $\begin{array}{l}0.9595 \\
(1.1786)\end{array}$ & $\begin{array}{l}0.0659 \\
(0.0156)\end{array}$ & $\begin{array}{l}0.9737 \\
(0.9965)\end{array}$ \\
\hline $12 \mathrm{P} 06 \mathrm{~F}$ & $\begin{array}{l}0.1288 \\
(0.1677)\end{array}$ & $\begin{array}{l}0.1790 \\
(0.2503)\end{array}$ & $\begin{array}{l}0.0106 \\
(0.0031)\end{array}$ & $\begin{array}{l}0.9994 \\
(0.9997)\end{array}$ & $\begin{array}{l}0.1431 \\
(0.1699)\end{array}$ & $\begin{array}{l}0.2047 \\
(0.2443)\end{array}$ & $\begin{array}{l}0.0145 \\
(0.0031)\end{array}$ & $\begin{array}{l}0.9992 \\
(0.9997)\end{array}$ & $\begin{array}{l}0.1694 \\
(0.2132)\end{array}$ & $\begin{array}{l}0.2413 \\
(0.3113)\end{array}$ & $\begin{array}{l}0.0167 \\
(0.0041)\end{array}$ & $\begin{array}{l}0.9983 \\
(0.9997)\end{array}$ \\
\hline $12 \mathrm{P} 12 \mathrm{~F}$ & $\begin{array}{l}0.3009 \\
(0.4389)\end{array}$ & $\begin{array}{l}0.4078 \\
(0.6262)\end{array}$ & $\begin{array}{l}0.0241 \\
(0.0079)\end{array}$ & $\begin{array}{l}0.997 \\
(0.9982)\end{array}$ & $\begin{array}{l}0.3596 \\
(0.4167)\end{array}$ & $\begin{array}{l}0.4901 \\
(0.5747)\end{array}$ & $\begin{array}{l}0.0344 \\
(0.0073)\end{array}$ & $\begin{array}{l}0.9962 \\
(0.9988)\end{array}$ & $\begin{array}{l}0.3448 \\
(0.4465)\end{array}$ & $\begin{array}{l}0.4739 \\
(0.601)\end{array}$ & $\begin{array}{l}0.0327 \\
(0.0079)\end{array}$ & $\begin{array}{l}0.9938 \\
(0.9991)\end{array}$ \\
\hline $12 \mathrm{P} 18 \mathrm{~F}$ & $\begin{array}{l}0.475 \\
(0.6524)\end{array}$ & $\begin{array}{l}0.6269 \\
(0.9026)\end{array}$ & $\begin{array}{l}0.0368 \\
(0.0114)\end{array}$ & $\begin{array}{l}0.9929 \\
(0.9963)\end{array}$ & $\begin{array}{l}0.5376 \\
(0.6428)\end{array}$ & $\begin{array}{l}0.7203 \\
(0.8551)\end{array}$ & $\begin{array}{l}0.0502 \\
(0.0109)\end{array}$ & $\begin{array}{l}0.9913 \\
(0.9975)\end{array}$ & $\begin{array}{l}0.535 \\
(0.6629)\end{array}$ & $\begin{array}{l}0.7107 \\
(0.8856)\end{array}$ & $\begin{array}{l}0.0488 \\
(0.0117)\end{array}$ & $\begin{array}{l}0.9858 \\
(0.998)\end{array}$ \\
\hline $12 \mathrm{P} 24 \mathrm{~F}$ & $\begin{array}{l}0.6718 \\
(1.0006)\end{array}$ & $\begin{array}{l}0.8799 \\
(1.3312)\end{array}$ & $\begin{array}{l}0.0514 \\
(0.0169)\end{array}$ & $\begin{array}{l}0.9861 \\
(0.9921)\end{array}$ & $\begin{array}{l}0.7994 \\
(0.9636)\end{array}$ & $\begin{array}{l}1.0478 \\
(1.2746)\end{array}$ & $\begin{array}{l}0.0725 \\
(0.0164)\end{array}$ & $\begin{array}{l}0.9818 \\
(0.9945)\end{array}$ & $\begin{array}{l}0.7411 \\
(1.0243)\end{array}$ & $\begin{array}{l}0.9716 \\
(1.3324)\end{array}$ & $\begin{array}{l}0.0663 \\
(0.0177)\end{array}$ & $\begin{array}{l}0.9742 \\
(0.996)\end{array}$ \\
\hline \multicolumn{13}{|c|}{ Wind Speed (Knots) } \\
\hline \multirow{2}{*}{$\begin{array}{l}\text { Forecast } \\
\text { Time }\end{array}$} & \multicolumn{4}{|l|}{ Train } & \multicolumn{4}{|c|}{ Verification } & \multicolumn{4}{|l|}{ Validation } \\
\hline & ARM & RMSE & SI & $\mathrm{CC}$ & ARM & RMSE & SI & $\mathrm{CC}$ & ARM & RMSE & SI & $\mathrm{CC}$ \\
\hline 06P 06F & 3.085 & 4.2322 & 0.0996 & 0.9772 & 3.2571 & 4.8692 & 0.1287 & 0.9735 & 3.5398 & 5.0605 & 0.11 & 0.9795 \\
\hline 06P 12F & 5.0849 & 7.0811 & 0.164 & 0.9365 & 5.6212 & 8.2533 & 0.2143 & 0.9233 & 6.4378 & 9.1879 & 0.1959 & 0.9327 \\
\hline 06P 18F & 7.0698 & 9.7056 & 0.2218 & 0.8801 & 7.6532 & 11.174 & 0.2854 & 0.8578 & 9.03 & 12.903 & 0.2702 & 0.8653 \\
\hline 06P 24F & 8.8106 & 11.931 & 0.2694 & 0.8174 & 9.5734 & 13.864 & 0.3488 & 0.7762 & 11.591 & 16.175 & 0.333 & 0.7849 \\
\hline $12 \mathrm{P} 06 \mathrm{~F}$ & 3.0419 & 4.2051 & 0.0974 & 0.978 & 3.2997 & 4.8726 & 0.1265 & 0.9739 & 3.5699 & 5.1055 & 0.1088 & 0.9797 \\
\hline $12 \mathrm{P} 12 \mathrm{~F}$ & 5.0169 & 7.0494 & 0.1611 & 0.9387 & 5.6424 & 8.2383 & 0.2104 & 0.9252 & 6.3792 & 9.1725 & 0.1921 & 0.9349 \\
\hline $12 \mathrm{P} 18 \mathrm{~F}$ & 6.9808 & 9.7024 & 0.2191 & 0.8835 & 7.6686 & 11.218 & 0.2822 & 0.8598 & 9.1124 & 13.035 & 0.2684 & 0.8668 \\
\hline $12 \mathrm{P} 24 \mathrm{~F}$ & 8.7629 & 11.952 & 0.2669 & 0.8224 & 9.5918 & 13.858 & 0.3438 & 0.7826 & 11.78 & 16.425 & 0.3329 & 0.7862 \\
\hline \multicolumn{13}{|c|}{ Pressure (hPa) } \\
\hline \multirow{2}{*}{$\begin{array}{l}\text { Forecast } \\
\text { Time }\end{array}$} & \multicolumn{4}{|l|}{ Train } & \multicolumn{4}{|c|}{ Verification } & \multicolumn{4}{|c|}{ Validation } \\
\hline & ARM & RMSE & SI & $\mathrm{CC}$ & ARM & RMSE & SI & $\mathrm{CC}$ & ARM & RMSE & SI & $\mathrm{CC}$ \\
\hline 06P 06F & 2.2318 & 3.8428 & 0.0038 & 0.9717 & 2.6246 & 4.161 & 0.0041 & 0.9674 & 3.4215 & 4.946 & 0.005 & 0.9665 \\
\hline 06P 12F & 3.7496 & 5.9774 & 0.006 & 0.9326 & 4.7196 & 7.1908 & 0.0072 & 0.9018 & 6.0367 & 8.4201 & 0.0085 & 0.9024 \\
\hline 06P 18F & 5.4029 & 8.5577 & 0.0086 & 0.8612 & 6.3798 & 9.7563 & 0.0098 & 0.8168 & 8.1882 & 11.266 & 0.0114 & 0.8221 \\
\hline 06P 24F & 6.6066 & 10.307 & 0.0103 & 0.7993 & 8.0948 & 12.076 & 0.0122 & 0.7242 & 9.9595 & 13.661 & 0.0138 & 0.7426 \\
\hline $12 \mathrm{P} 06 \mathrm{~F}$ & 2.2772 & 3.7356 & 0.0037 & 0.9741 & 2.6854 & 4.2219 & 0.0042 & 0.9671 & 3.5482 & 5.0836 & 0.0051 & 0.9654 \\
\hline $12 \mathrm{P} 12 \mathrm{~F}$ & 3.8243 & 6.1372 & 0.0061 & 0.9314 & 4.56 & 7.2014 & 0.0072 & 0.9034 & 6.0451 & 8.4673 & 0.0085 & 0.9034 \\
\hline $12 \mathrm{P} 18 \mathrm{~F}$ & 5.4258 & 8.5138 & 0.0085 & 0.8683 & 6.285 & 9.6772 & 0.0097 & 0.8299 & 8.136 & 11.327 & 0.0114 & 0.8297 \\
\hline 12P 24F & 6.6914 & 10.437 & 0.0105 & 0.8047 & 8.0294 & 11.953 & 0.012 & 0.7341 & 9.8206 & 13.467 & 0.0136 & 0.7548 \\
\hline
\end{tabular}


The difference between land crossing point by the JTWC best tracks and the ANN predicted tracks are given in table 3 . By using the 12 hours past position for 12 hours and 24 hours forecasts. For 12 hours prediction the minimum error is $3.8 \mathrm{~km}$ and the maximum error is $124.8 \mathrm{~km}$ with a mean value of 38.2 $\mathrm{km}$. For 24 hour forecasts, the minimum error is $0.26 \mathrm{~km}$ and the maximum error is $192.56 \mathrm{~km}$ with a mean value of $71.2 \mathrm{~km}$ for $24 \mathrm{hours}$ prediction.

Table-3: Land crossing difference between the best tracks and ANN predicted tracks.

\begin{tabular}{|c|c|c|c|c|c|}
\hline \multicolumn{3}{|c|}{12 Hrs past 12 Hrs forecast } & \multicolumn{3}{|c|}{12 Hrs past $24 \mathrm{Hrs}$ forecast } \\
\hline SI. No & Year - Cyclone No. & Length (km) & SI. No & Year - Cyclone No. & Length (km) \\
\hline 1 & $2008-66$ & 43.72 & 1 & $2008-95$ & 18.06 \\
\hline 2 & $2008-90$ & 6.19 & 2 & $2009-26$ & 48.47 \\
\hline 3 & $2008-95$ & 24.62 & 3 & $2010-24$ & 159.47 \\
\hline 4 & $2009-26$ & 17.61 & 4 & $2010-80$ & 50.51 \\
\hline 5 & $2009-64$ & 8.92 & 5 & $2011-94$ & 49.77 \\
\hline 6 & $2009-89$ & 61.13 & 6 & $2012-81$ & 87.88 \\
\hline 7 & 2010-24 & 42.4 & 7 & $2012-84$ & 62.61 \\
\hline 8 & $2010-80$ & 5.94 & 8 & 2013-75 & 43.31 \\
\hline 9 & 2011-94 & 33.79 & 9 & 2013-93 & 192.56 \\
\hline 10 & $2012-81$ & 10.61 & 10 & $2013-94$ & 38.68 \\
\hline 11 & $2012-84$ & 17.9 & 11 & $2014-75$ & 66.58 \\
\hline 12 & 2013-75 & 14.18 & 12 & 2016-91 & 70.06 \\
\hline 13 & 2013-93 & 51.31 & 13 & 2016-92 & 66.05 \\
\hline 14 & 2013-94 & 35.76 & 14 & $2018-93$ & 79.98 \\
\hline 15 & 2013-99 & 79.99 & 15 & $2018-102$ & 43.73 \\
\hline 16 & 2014-75 & 34.29 & 16 & $2018-105$ & 129.32 \\
\hline 17 & 2016-91 & 19.35 & 17 & 2019-87 & 0.26 \\
\hline 18 & 2016-92 & 14.83 & & & \\
\hline 19 & $2018-82$ & 89.1 & & Mean & 71.02 \\
\hline 20 & 2018-93 & 48.78 & & Max & 192.56 \\
\hline 21 & $2018-102$ & 3.8 & & Min & 0.26 \\
\hline 22 & $2018-105$ & 80.42 & & & \\
\hline 23 & 2019-21 & 47.56 & & & \\
\hline \multirow[t]{4}{*}{24} & 2019-87 & 124.8 & & & \\
\hline & Mean & 38.21 & & & \\
\hline & Max & 124.8 & & & \\
\hline & Min & 3.8 & & & \\
\hline
\end{tabular}

\section{Summary And Conclusions:}

An ANN approach has been used to predict the cyclone parameters (position in terms of latitude and longitude, wind speed and pressure). The predicted track is used to estimate the landfall point. After a quality check, 323 cyclones were used for the position, 239 cyclones for wind speed and 104 cyclones for pressure. Since ANN needs a large amount of data, each cyclone was divided into segments to increase the number of points. All together 8 sets of data have been studied with past 6 and 12 hours, each of these past hours having the prediction for $06,12,18$ and 24 hours.

The SI for longitude being less than that for latitude indicates that the zonal component of the cyclone can be predicted better than the meridional component. The correlations consistently support this assessment. However, the RMSE (which is more relevant to emergency managers) is greater for longitude than for latitude. The MDE increases with the lead time in case of both 6 and 12 hours past positions. A comparison of the best track from JTWC and ANN-predicted track for the four cyclones randomly selected from the validation dataset match satisfactorily as described below. Four cyclones have been selected having different tracks such as looped, curved, re-tracked of the validation dataset. The MDE of these four cyclones varies between $53.1 \mathrm{~km}$ and $87.8 \mathrm{~km}$. 
SI of wind speed for the validation dataset varying between 0.11 to 0.33 , with a CC of more than 0.7 is quite acceptable. As in the case of the predictions of the position, the SI for the wind speed also increases with lead time. Secondly, whether we use the past 6 hours or 12 hours the errors almost remain the same.

The SI for the pressure estimation of the validation dataset is very negligible, varying from 0.005 to 0.01 with a correlation of more than 0.7 . the high values of RMSE are understandable because the pressure values are in the range of $1000 \mathrm{hPa}$. As in the case of the previous two parameters, the SI increases with the lead time and remains similar for the past 6 and 12 hours predictions.

The difference between the JTWC best track and the ANN predictions of the landfall crossing points and the time of crossing the land has a mean error of $38.4 \mathrm{~km}$ for the 12 hours forecast and $71.02 \mathrm{~km}$ for the 24 hours forecast. By analysing the 33 cyclones in the north Indian Ocean during $2003-2013$, Mohapatra et al., (2015) obtained an average error of $69 \mathrm{~km}$ for 12 hour forecast and $104 \mathrm{~km} 24$ hour forecast. Compared to these errors, the errors obtained by the ANN predictions are far better. However, Mohapatra et al., could predict 72 hours in advance, which could not be done in this paper. Since advance notice is very critical the error of $71.02 \mathrm{~km}$ needs to be considered.

\section{Declarations:}

\section{Acknowledgments:}

The authors thank the concerned departments for their support. Cyclone parameters data used from IBTrACS (International Best Track Archive for Climate Stewardship). The authors have no conflict of interest in any way.

\section{Ethical Statement:}

This manuscript is not currently being considered for publication elsewhere. All sources used are properly disclosed. Literally copying of text must be indicated as such by using quotation marks and giving proper reference. The results are appropriately placed in the context of prior and existing research. This material is the authors' own original work, which has not been previously published elsewhere. Data used in this manuscript is acknowledged.

\section{References:}

1. Ali M. M., D. Swain, and R. A. Weller (2004), Estimation of ocean subsurface thermal structure from surface parameters: A neural network approach, Geophys. Res. Lett., 31, L20308, doi:10.1029/ 2004GL021192.

2. Ali M.M., Kishtawal, C. M. and Sarika Jain (2007), Predicting cyclone tracks in the north Indian Ocean: An artificial neural network approach, Geophysical Research Letters, Vol. 34, L04603, doi:10.1029 /2006GL028353.

3. Ali M. M., Jagadeesh P. S. V, Jain S (2007), Effects of eddies and dynamic topography on the Bay of Bengal cyclone intensity. Eos, Transactions of the American Geophysical Union 88: 93-95.

4. Ali M. M., Jagadeesh PSV, Lin I-I, Hsu J-Y (2012a), A neural network approach to estimate tropical cyclone heat potential in the Indian Ocean. IEEE Geoscience and Remote Sensing Letters 9: 1114-1117, DOI: 10.1109/LGRS.2012.2190491.

5. Ali M. M., Swain D, Kashyap T, McCreary JP, Nagamani PV (2012b), Relationship between cyclone intensities and sea surface temperature in the Tropical Indian Ocean. IEEE Geoscience and Remote Sensing Letters 10: 841-844, DOI: 10.1109/LGRS.2012.2226138.

6. Ali M. M., Jagadeesh P. S. V., Lin I-I, Hsu J-Y (2012c), A neural network approach to estimate tropical cyclone heat potential in the Indian Ocean. IEEE Geoscience and Remote Sensing Letters 9: 1114-1117, DOI: 10.1109/LGRS.2012.2190491.

7. Ali M. M., Bhowmick S.A., Sharma R., Chaudhury A., Pezzullo J.C., Bourassa M.A., Ramana I.V. and Niharika K., (2015), An artificial neural network model function (AMF) for saral-altika winds. IEEE Journal of Selected Topics in Applied Earth Observations and Remote Sensing, 8(11), pp.5317-5323.

8. Ali M. M., Bourassa M. A., Bhowmick S. A., Sharma R., \& Niharika K. (2016), Retrieval of Wind Stress at the Ocean Surface From AltiKa Measurements. IEEE Geoscience and Remote Sensing Letters, 13(6), 821-825.

9. Bell G. J., (1979), Operational forecasting of tropical cyclones, Aust. Meteorol. Mag., 27, $249-258$.

10. Gupta A., (2006), Current status of tropical cyclone track prediction techniques and forecast errors, Mausam, $57(1), 151$ - 158.

11. Jain S., and M. M. Ali (2006), Estimation of sound speed profiles using artificial neural network, IEEE Trans. Geosci. Remote Sens. Lett., 3(4), $467-470$.

12. Jain S, Ali MM, Sen PN. 2007. Estimation of sonic layer depth from surface parameters. Geophyical Research Letters 34: LI7602, DOI: 10.1029/2007GL030577.

13. Jain S, Ali MM, Sen PN. 2007. Estimation of sonic layer depth from surface parameters. Geophyical Research Letters 34: LI7602, DOI: 10.1029/2007GL030577.

14. Jain S., Ali MM., Sen PN (2007), Estimation of sonic layer depth from surface parameters. Geophyical Research Letters 34: LI7602, DOI: $10.1029 / 2007$ GL030577.

15. Krasnopolsky V., Schiller H., (2003) Some neural network applications in environmental sciences part I: forward and inverse problems in satellite remote sensing. Neural Networks 16: 321-334.

16. Lazo, J.K., Waldman, D.M., Morrow, B.H. and Thacher, J.A., 2010. Household evacuation decision making and the benefits of improved hurricane forecasting: Developing a framework for assessment. Weather and Forecasting, 25(1), pp.207-219. 
17. Liu QH, Simmer C, Ruprecht E., (1997) Estimating longwave net radiation at sea surface from the Special Sensor Microwave/Imager (SSM/I). Journal of Applied Meteorology 36: 919-930.

18. Mohanty U. C., and A. Gupta., (1997), Deterministic methods for prediction of tropical cyclone tracks, Mausam, $48(2), 257$ - 272.

19. Mohapatra, M., Nayak, D.P., Sharma, M. (2015). Evaluation of official tropical cyclone landfall forecast issued by India Meteorological Department. J Earth Syst Sci 124, 861-874.

20. Patoux J, Foster RC, Brown RA. (2003). Global pressure fields from scatterometer winds. Journal of Applied Meteorology 42: 813-826.

21. Purna Chand, C., Rao, M. V., Ramana, I. V., Ali, M. M., Patoux, J., \& Bourassa, M. A. (2014). Estimation of sea level pressure fields during Cyclone Nilam from Oceansat-2 scatterometer winds. Atmospheric Science Letters, 15(1), 65-71.

22. Sharma N, Ali MM., (2012), A neural network approach to improve the vertical resolution of atmospheric temperature profiles from geostationary satellites. IEEE Geoscience and Remote Sensing Letters 10: 34-37, DOI: 10.1109/LGRS.2012.2191763.

23. Sharma Neerja., Ali MM., Knaff John, Chand C Purna., (2013), A soft-computing cyclone intensity prediction scheme for the Western North Pacific Ocean. Atmospheric Science Letters. 14. 10.1002/asl2.438.

24. Swain Debadatta., Ali MM., Weller Robert., (2006), Estimation of mixed-layer depth from surface parameters. Journal of Marine Research. 64. $10.1357 / 002224006779367285$.

25. Tolman Hendrik., Krasnopolsky Vladimir., and Chalikov Dmitry., (2005), Neural network approximations for nonlinear interactions in wind wave spectra: Direct mapping for wind seas in deep water. Ocean Modelling. 8. 253-278. 10.1016/j.ocemod.2003.12.008.

26. Willoughby, H.E., Rappaport, E.N. and Marks, F.D., 2007. Hurricane forecasting: The state of the art. Natural Hazards Review, 8(3), pp.45-49.

\section{Figures}

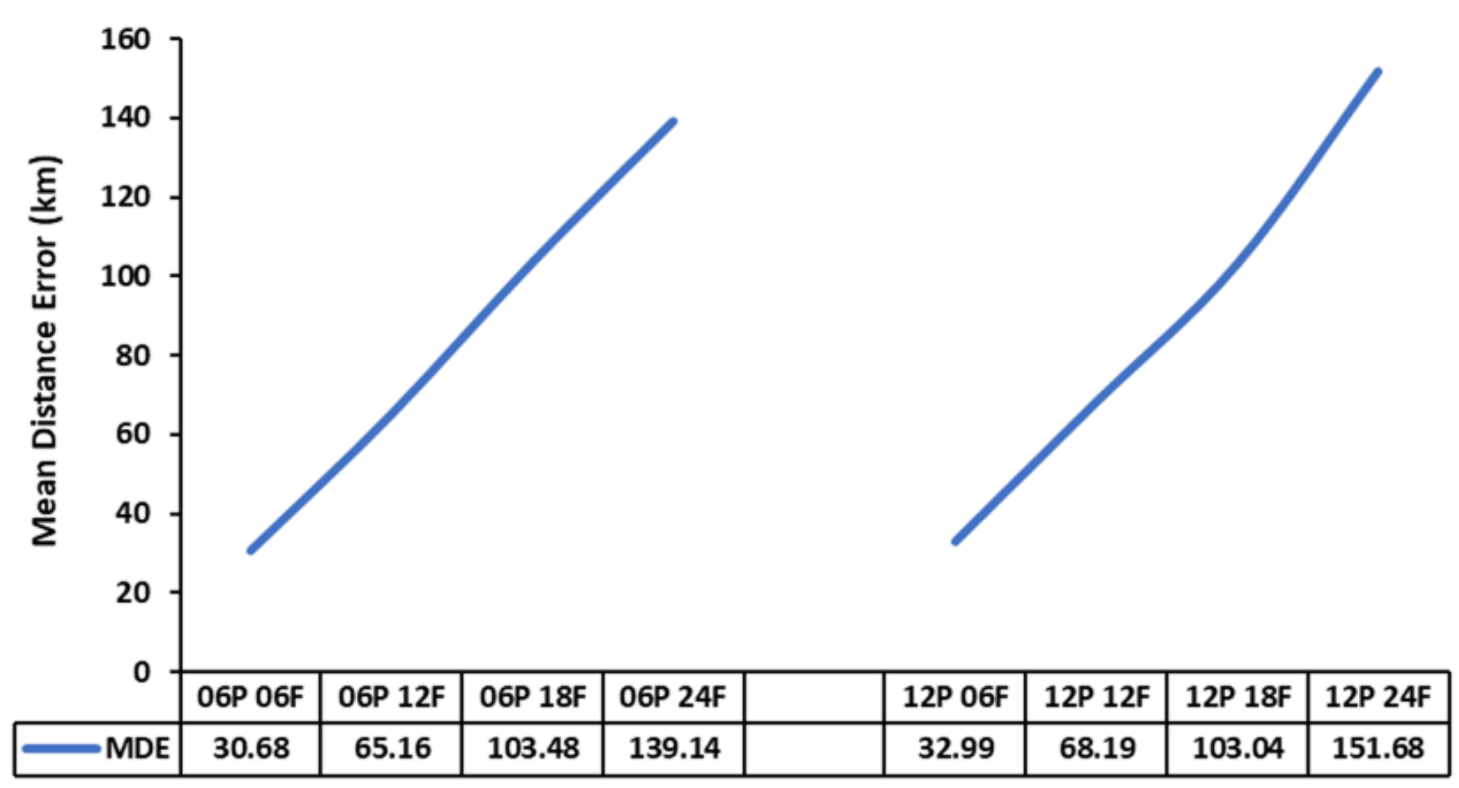

Figure 1

Mean Distance Error for different time period with 06 and 12-hours past with 06 hours interval data. 

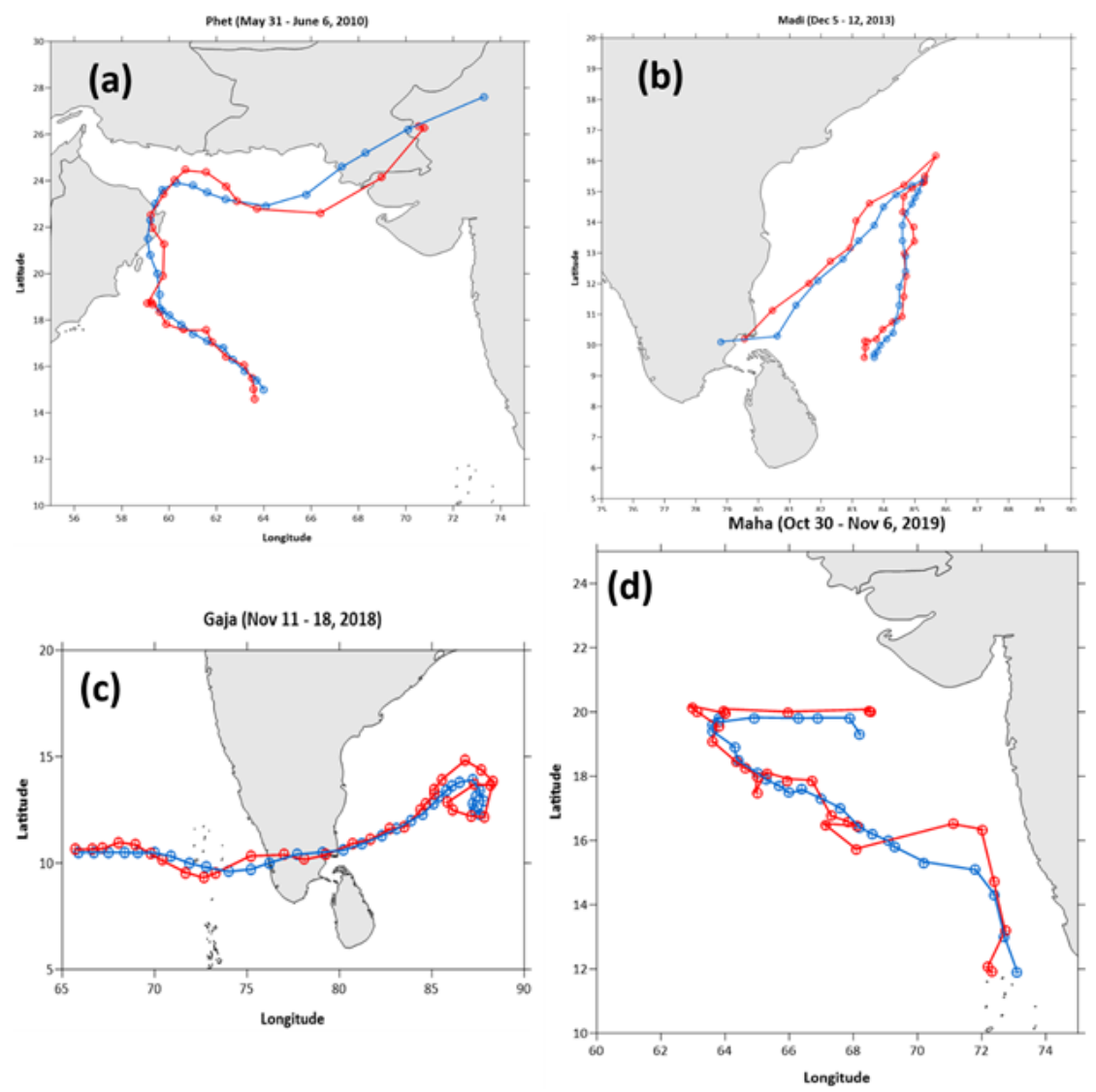

Figure 2

A comparison of the best track from JTWC (blue colour) and the predicted tracks from ANN (red colour) of the cyclones during (a) 31 May - 6 June 2010 (Very Severe Cyclonic Storm Phet); (b) 5 - 12 December 2013 (Very Severe Cyclonic Storm Madi); (c) 11 - 18 November 2018 (Very Severe Cyclonic Storm Gaja); and (d) 30 October - 6 November 2019 (Extremely Severe Cyclonic Storm Maha).
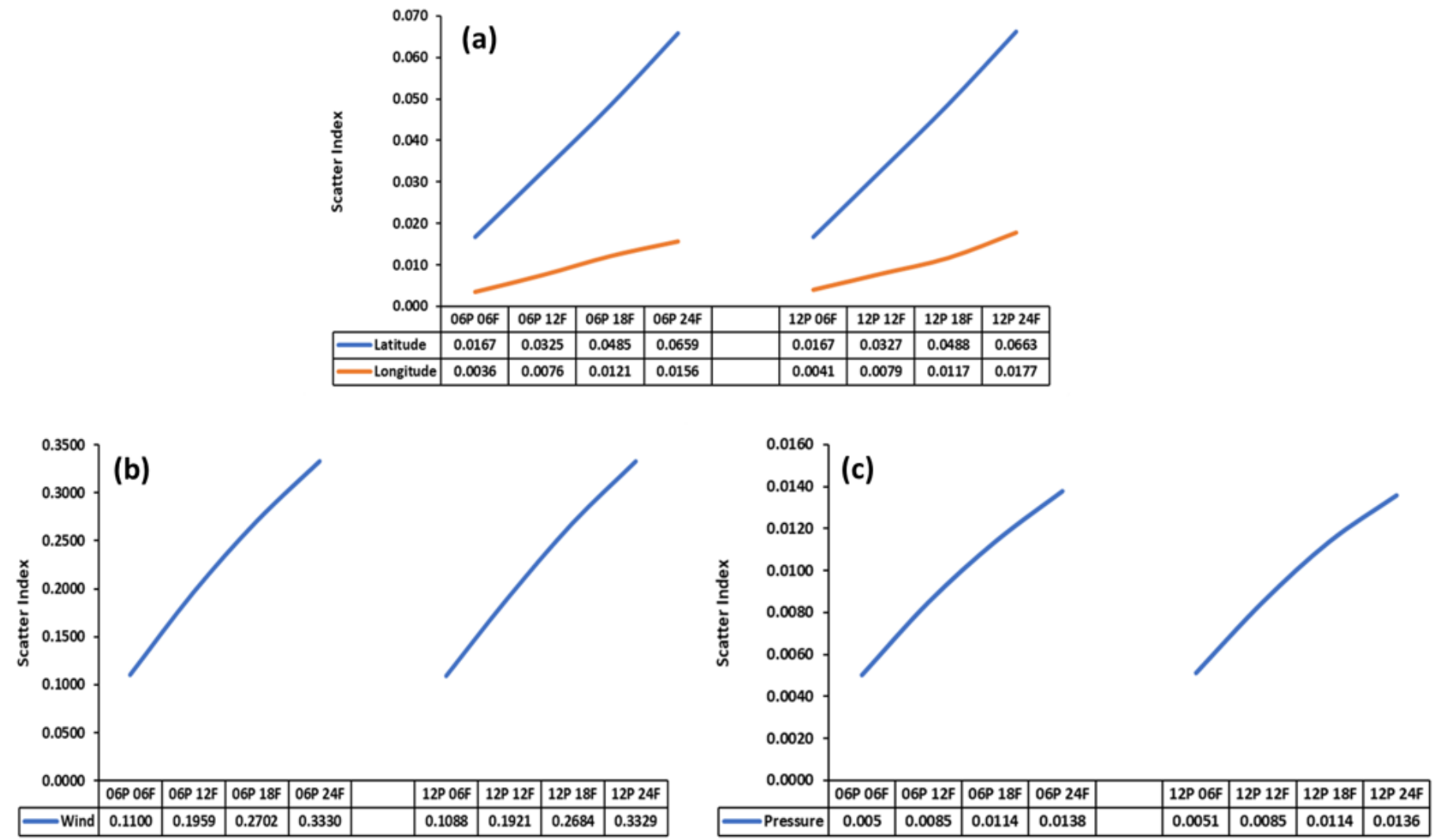
Figure 3

Scatter Index of (a) Latitude and Longitude, (b) Wind Speed and (c) Pressure for the different lead times of 06 and 12 -hours and with past 06 hours interval data 'xxP yyF' means xx Past hours and yy Forecast hour. 